\title{
Prevalence and Associated Factors of Burnout among Doctors in Yemen
}

\author{
Sami Abdo Radman Al-Dubai and Krishna Gopal Rampal
}

Department of Community Health, Faculty of Medicine, Universiti Kebangsaan Malaysia, Medical Center, Malaysia

\begin{abstract}
Prevalence and Associated Factors of Burnout among Doctors in Yemen: Sami Abdo Radman AL-DuBAl, et al. Department of Community Health, Faculty of Medicine, Universiti Kebangsaan Malaysia, Medical Center, Malaysia-Objectives: This study aimed to determine the level and factors contributing to burnout among doctors in Sana'a City, Yemen and to determine the relationship between burnout and psychological morbidity. Methods: This was a cross-sectional study of 563 working doctors in the four main hospitals in Sana'a City, Yemen. The 12 -item version of the General Health Questionnaire (GHQ12) was used as a measure of psychological morbidity and the 22-item Maslach Burnout Inventory (MBI) was used to measure emotional exhaustion, depersonalization, and personal accomplishment. Sources of job stress were determined using a 37-item scale questionnaire. The questionnaire elicited information about socio-demographic and work characteristics. Results: On the MBI, 356 doctors showed high emotional exhaustion (63.2\%), 109 showed high depersonalization (19.4\%) and 186 showed low personal accomplishment (33.0\%). Sixty six doctors $(11.7 \%)$ were identified as experiencing a high degree of burnout (high emotional exhaustion and depersonalization and low personal accomplishment). The prevalence of high degree of burnout was significantly higher in those with duration of work $\leq 10$ $\mathrm{yr}(\mathrm{OR}=2.8,95 \% \mathrm{Cl} 1.18-6.8)$, in those working $\geq 40 \mathrm{~h} /$ wk $(\mathrm{OR}=2.1,95 \% \mathrm{Cl} 1.25-3.62)$ and in those who had psychological morbidity (OR=5.3, 95\% Cl 2.22-12.39). Thirteen out of 37 sources of stress were significantly associated with high degree of burnout. In multivariate analysis, the significant predictors of high burnout were: dealing with patient's psychosocial problems, feeling of isolation, disturbance of home/family life by work,
\end{abstract}

Received Dec 17, 2008; Accepted Sep 21, 2009

Published online in J-STAGE Nov 10, 2009

Correspondence to: S.A.R. Al-Dubai, Department of Community Health, Faculty of Medicine, Universiti Kebangsaan Malaysia, Medical Center, Jalan Yaacob Latif, Bandar Tun Razak, Cheras 56000, Kuala Lumpur, Malaysia

(e-mail: samidobaie@yahoo.com) not chewing khat, long working hours and psychological morbidity. Conclusion: The prevalence of high degree of burnout as well as emotional exhaustion in Yemeni doctors was higher than those reported internationally and was associated with psychological morbidity and many important sources of job stress.

(J Occup Health 2010; 52: 58-65)

Key words: Burnout, Doctors, Emotional exhaustion, Yemen

Burnout is "a syndrome of emotional exhaustion, depersonalization, and reduced personal accomplishment that can occur among individuals who do people work of some kind" and it refers to a negative consequence of chronic work stress ${ }^{1)}$. Burnout has been associated with physical illness and mental health problems ${ }^{1)}$. It may also lead to alcohol and drug abuse and deterioration in relationships with family and friends ${ }^{2}$. At the organizational level, burnout and stress are associated with negative organizational outcomes such as lack of concentration, poor timekeeping, poor productivity, difficulty in comprehending new procedures, lack of cooperation, irritability, aggressiveness, resentment and increased tendency to make mistakes ${ }^{3,4}$. The components of burnout are common among practicing physicians, with $46 \%$ to $80 \%$ reporting moderate to high levels of emotional exhaustion, $22 \%$ to $93 \%$ reporting moderate to high levels of depersonalization and $16 \%$ to $79 \%$ reporting low to moderate levels of personal accomplishment ${ }^{5)}$. Many factors are associated with burnout; these include, time pressure, role conflict and role ambiguity, lack of support from supervisors and coworkers, the severity of clients' problems, frequency of contact with chronically or terminally ill patients and confrontation with death and dying ${ }^{1)}$. Workload-related factors, such as long working hours, frequency of oncall duties and work-home interference have been identified by previous studies as determinants of job strain $^{6}$ and burnout ${ }^{1)}$ among medical doctors. In addition, stress in the workplace (measured by the General Health Questionnaire $)^{7)}$ and job satisfaction are also important 
factors associated with burnout ${ }^{8}$.

Yemen is a Middle Eastern country located on the Arabian Peninsula in Southwest Asia with a population of 21.5 million people. Yemen is a country with poor health indicators (2.2 physicians and 6.1 hospital beds per 10,000 population $)^{9)}$. There is a lack of studies on burnout among doctors and its associated factors in Yemen. This study attempted to determine the prevalence and the associated factors of burnout among Yemeni doctors. These factors include socio-demographic and work characteristics, psychological morbidity and sources of job stress in the workplace.

\section{Subjects and Methods}

\section{Participants}

A total of 800 questionnaires were distributed manually by the researcher to all the available doctors (specialists and non- specialists) in the four main government hospitals in Sana'a City, Yemen in the period from December 2006 to July 2007. Five hundred and sixtythree doctors returned complete questionnaire with an observed response rate of $70.4 \%$. Doctors with less than one year duration of work and/or those who worked in the private sector only were excluded from this study.

\section{Research instruments}

A) Socio-demographic and work characteristics

A questionnaire was developed for this study to obtain demographic and work characteristics. The sociodemographic factors included gender, age, qualification (general practitioners or specialist), marital status, type of residence and chewing khat. Chewing the fresh leaves of khat (catha edulis) is common and legal in East Africa and Yemen. It is both a social and a culture-based activity in Yemen. It is used as a stimulant as it contains cathine and cathinon that have an amphetamine like effect. The work characteristics included length of employment, type of employment, number of working hours per week and total income.

\section{B) Burnout}

Burnout was measured by the Maslach Burnout Inventory-Human Services Survey (MBI-HSS) which is the most commonly used tool for assessing burnout. It consists of 22 items which are divided into three subscales: emotional exhaustion, 9 items (the feelings of being emotionally overrun and exhausted by one's work); depersonalization, 5 items (the tendency to view others as objects rather than as feeling persons) and personal accomplishment, 8 items (the degree to which a person perceives doing well on worthwhile tasks ${ }^{10,11)}$. The items are answered in terms of the frequency with which the respondent experiences these feelings, on a 7-point scale ranging from 0 (never) to 6 (every day $)^{10,11)}$. The three scores are calculated for each respondent. A higher score indicates greater burnout except for the personal accomplishment scale which is rated inversely. Specifically, a high degree of burnout is represented by high scores of emotional exhaustion $(\geq 27)$ and depersonalization $(\geq 13)$ and low scores of personal accomplishment $(\leq 31)^{1)}$. The MBI-HSS questionnaire was translated to Arabic by a professional translator. The translated version was compared with the English version by the principal author to ensure it reflected the original message. Exploratory and confirmatory factor analysis were performed to confirm the three-factor structure of the final Arabic version of the MBI-HSS questionnaire. The internal consistency was assessed by Cronbach's alpha coefficient. We followed the original classification of the MBI-HSS because there was no specific cut-off points to use among Yemenis.

C) Psychological morbidity

The 12-item version of the General Health Questionnaire was used to measure psychological morbidity. Scoring was on a $0-0-1-1$ basis (i.e. a score of 0 or 1 was given a value of 0 and a score of 2 or 3 was given a value of 1). This can be scored 0 to 12 . Psychological morbidity was defined as a score of 4 or more on the GHQ-12; this approach was used in previous studies $^{12,13)}$.

D) Sources of job stress

Sources of job stress were determined by a 37-item scale questionnaire. This questionnaire was used in a previous study ${ }^{13)}$ and was modified for the purpose of this study. Each item was scored on a six-point Likert scale, where a value of zero equals not applicable and a value of five refers to strongly agree.

\section{Statistical methods}

Data analysis was performed using "Statistical Package for Social Sciences (SPSS) version 13. After all data was entered into SPSS, they were reviewed for the accuracy of data entry. All the continuous sociodemographic and work characteristic variables were categorized. Sources of job stress scales were categorized to ease interpretation into 3 categories by combining the response categories "agree" and "strongly agree" into one category (agree), "not agree" and "strongly not agree" into one category (disagree) and "inapplicable" and "undecided" into one category. The three subscale scores of the MBI-HSS were specified as three separate criterion variables. Raw scores of the three subscales were summed and then were transformed into low, moderate or high. We then defined 'high degree of burnout' as high emotional exhaustion and depersonalization and low personal accomplishment. Descriptive statistics of the high degree of burnout across the socio-demographic and 
work characteristics were done. Differences in the prevalence of 'high degree of burnout' were tested with the Chi-square test (Yates' correction) for binomial variables. In cases of variables with three categories, odds ratios (OR) were obtained by simple logistic regression. Multiple logistic regression analysis was performed to obtain the most important predictors of high burnout. A logistic regression coefficient was used to estimate the odds ratios for each of the independent variables in the model. A $p$ value $<0.05$ was used as the level of significance.

\section{Results}

Socio-demographic and work characteristics

Of the 563 respondents, 335 (59.5\%) were males, 169 $(30.0 \%)$ were specialists, $195(34.6 \%)$ were single, 352 $(62.6 \%)$ married and 16 (2.8\%) divorced or widowed. The mean age of doctors was $33.3 \pm 5.7 \mathrm{yr}$ and the age ranged from 25 to $55 \mathrm{yr}$. Only sixty-seven (11.9\%) had their own houses while $496(88.1 \%)$ did not have their own houses. Two hundred and forty-eight (44\%) chewed khat. One hundred fifteen doctors $(20.4 \%)$ had spent more than ten years at their work. The median number of working hours with the government was $40 \mathrm{~h}$ per week and ranged from 24 to $92 \mathrm{~h}$. Two hundred and ninetyfour doctors $(52.2 \%)$ were employed by the government only, while two hundred and sixty nine $(47.8 \%)$ were employed by the government and also working in the private sector. Four hundred and thirty-three doctors (77.5\%) received less than 40,000 Yemeni Rial/month (Table 1).

\section{Factorial based validity and internal consistency of the MBI-HSS}

Factorial validity of the MBI was examined using exploratory and confirmatory factor analysis (Quartimax rotations). It showed that the Arabic version of the MBI inventory measures has three factors, depersonalization, emotional exhaustion, and personal accomplishment, a result which supports the three-factor structure of the MBI-HSS. Cronbach's alpha coefficient for the three MBI subscales in this study were: emotional exhaustion (alpha $=0.88)$, depersonalization $($ alpha $=0.78)$, personal accomplishment (alpha $=0.89$ ). This indicates that the MBI-HSS is a valid and a reliable instrument for measuring burnout among Yemeni doctors.

\section{Degree and prevalence of burnout subscales}

Mean scores were obtained for each of the three MBI subscales (Table 2). For the emotional exhaustion and depersonalization subscales, high mean scores reflect high levels of burnout, whereas for the personal accomplishment subscale low scores reflect high levels of burnout. Emotional exhaustion, depersonalization, and personal accomplishment were categorized into low,
Table 1. Socio-demographic and social characteristics of respondents $(\mathrm{N}=563)$ : Cross- sectional study of burnout among doctors in Yemen $(\mathrm{N}=563)$

\begin{tabular}{|c|c|c|}
\hline Variables & $\mathrm{N}$ & $\%$ \\
\hline \multicolumn{3}{|l|}{ Gender } \\
\hline Male & 335 & 59.5 \\
\hline Female & 228 & 40.5 \\
\hline \multicolumn{3}{|l|}{ Age groups (yr) } \\
\hline$\leq 29$ & 180 & 32.0 \\
\hline $30-39$ & 308 & 54.7 \\
\hline$\geq 40$ & 75 & 13.3 \\
\hline \multicolumn{3}{|l|}{ Qualification } \\
\hline Specialist & 169 & 30.0 \\
\hline Non-specialist & 394 & 70.0 \\
\hline \multicolumn{3}{|l|}{ Marital status } \\
\hline Single & 195 & 34.6 \\
\hline Married & 352 & 62.6 \\
\hline Divorce or widowed & 16 & 2.8 \\
\hline \multicolumn{3}{|l|}{ Chewing khat } \\
\hline Yes & 248 & 44.0 \\
\hline No & 315 & 56.0 \\
\hline \multicolumn{3}{|l|}{ Residence } \\
\hline House owner & 67 & 11.9 \\
\hline Not a house owner & 496 & 88.1 \\
\hline \multicolumn{3}{|l|}{ Type of employment } \\
\hline Government only & 294 & 52.2 \\
\hline Government and private sector & 269 & 47.8 \\
\hline \multicolumn{3}{|l|}{ Duration of work in years } \\
\hline$\leq 10$ & 448 & 79.6 \\
\hline$>10$ & 115 & 20.4 \\
\hline \multicolumn{3}{|c|}{ Hours of work with the government/wk } \\
\hline$\leq 40$ & $306 *$ & 54.9 \\
\hline$>40$ & 251 & 45.1 \\
\hline \multicolumn{3}{|c|}{ Income from the government/mo (Yemeni Rial) } \\
\hline$\leq 40,000$ & $433 *$ & 77.5 \\
\hline$>40,000$ & 126 & 22.5 \\
\hline
\end{tabular}

* Total is not 563 due to non response.

Table 2. Average scores of subscales of the Maslach Burnout Inventory Human Service Survey (MBI-HSS) among doctors in Yemen $(\mathrm{N}=563)$

\begin{tabular}{lrrc}
\hline Burnout subscales & Mean & SD & 95\% CI \\
\hline Emotional exhaustion & 31.3 & 13.0 & $30.2-32.3$ \\
Depersonalization & 7.2 & 6.7 & $6.7-7.8$ \\
Personal accomplishment & 35.7 & 10.1 & $34.9-36.5$ \\
\hline
\end{tabular}

$\mathrm{SD}=$ standard deviation; $95 \% \mathrm{CI}=95 \%$ confidence interval. 
Table 3. Prevalences of burnout based on each subscale of Maslach Burnout Inventory-Human Service Survey (MBI-HSS) among doctors in Yemen $(\mathrm{N}=563)$

\begin{tabular}{lccc}
\hline \multirow{2}{*}{ Burnout subscales } & Low & Moderate & High \\
\cline { 2 - 4 } & $\mathrm{N}(\%)$ & $\mathrm{N}(\%)$ & $\mathrm{N}(\%)$ \\
\hline Emotional exhaustion & $110(19.6)$ & $97(17.2)$ & $356(63.2)$ \\
Depersonalization & $315(56.0)$ & $139(24.6)$ & $109(19.4)$ \\
Personal accomplishment & $186(33.0)$ & $143(25.4)$ & $234(41.6)$ \\
\hline
\end{tabular}

The classification of high, moderate and low levels of burnout was based on the original classification according to the MBI-HSS.

moderate or high by summing their raw scores and then by transforming the summation of scores into categorizations of low, moderate or high (Table 3 ).

On the MBI, 356 doctors (63.2\%) showed high emotional exhaustion, 97 (17.2\%) showed moderate emotional exhaustion and $110(19.6 \%)$ showed low emotional exhaustion. One hundred and nine doctors (19.4\%) showed high depersonalization, 139 (24.6\%) showed moderate depersonalization and 315 (56.0\%) showed low depersonalization. One hundred and eightysix (33.0\%) showed low personal accomplishment, 143 (25.4\%) showed moderate personal accomplishment and $234(41.6 \%)$ showed high personal accomplishment (Table 3).

\section{Prevalence of high degree of burnout}

Specifically, a high degree of burnout is represented by high scores of emotional exhaustion $(\geq 27)$ and depersonalization $(\geq 13)$ and low scores of personal accomplishment $(\leq 31)^{10)}$. Based on these categorizations, sixty-six doctors $(11.7 \%)$ were identified as experiencing a high degree of burnout.

\section{High degree of burnout by socio-demographic and work} characteristics

The prevalence of high degree of burnout was significantly higher among those aged $\leq 29$ than those aged $\geq 40$ yr old $(\mathrm{OR}=4.2,95 \%$ CI $1.2-14.4, p=0.021)$. It was also higher among those who did not chew khat than among those who did $(\mathrm{OR}=3.7,95 \%$ CI 1.9-6.9, $p<0.005)$. There was no significant association between burnout and the other socio-demographic variables (Table 4).

Regarding work characteristics, the prevalence of high degree of burnout was significantly higher among those with a duration of work $\leq 10 \mathrm{yr}$ than among those with more than $10 \mathrm{yr}$ work duration $(\mathrm{OR}=2.8,95 \%$ CI 1.2$6.8, p=0.015$ ); among those working for the government only than among those working for both government and private sector $(\mathrm{OR}=2.7,95 \%$ CI 1.5-4.8, $p<0.005)$; among those working more than $40 \mathrm{~h} /$ week for the government than among those working $\leq 40 \mathrm{~h} / \mathrm{wk}(\mathrm{OR}=2.1,95 \% \mathrm{CI}$ $1.3-3.6, p=0.005$ ); and among those with income $\leq 40,000$ Yemeni Rial/month from the government than among those with income more than 40,000 Yemeni Rial $(\mathrm{OR}=2.7,95 \%$ CI 1.2-6.0, $p=0.013$ ) (Table 4).

Association between high degree of burnout and psychological morbidity and sources of job stress in the workplace

High burnout was significantly associated with psychological morbidity; those who had psychological morbidity were more likely to be burned out than those who did not (OR=5.3, 95\% CI 2.2-12.4, $p<0.005)$. Regarding sources of job stress in the workplace, thirteen out of 37 items were associated significantly with high degree of burnout: dealing with problem patients, uncertainty and insecurity, lack of comfortable rooms for doctors on call, poor status in the eyes of your seniors, dealing with patient's psychosocial problems, feeling of isolation, managing the practice, working environment, difficulty in finding a locum, lack of appreciation from patients, increased work load, disturbance of home/family life by work and long working hours. The association between each item and burnout was assessed using simple logistic regression (Table 5).

\section{Multivariate analysis of high degree of burnout}

The socio-demographic and work characteristic variables which were significantly associated with burnout in the bivariate analysis were analysed by multiple logistic regression to obtain the first model. Variables entered were: age groups, chewing khat, duration of work, type of employment, hours of work with the government/week and income from the government as well as psychological morbidity. Sources of job stress which were associated significantly with burnout were entered in a separate model. These two models were combined to obtain the final model. Enter technique was used and the highest non-significant variables were removed manually in each step. Variables which remained significant in the model were: 
Table 4. Prevalence of burnout and the odds ratios associated with socio-demographic and social characteristics among doctors in Yemen $(\mathrm{N}=563)$

\begin{tabular}{|c|c|c|c|c|}
\hline Variables & $\begin{array}{l}\text { High burnout* } \\
(\%)\end{array}$ & OR & $95 \% \mathrm{CI}$ & $p$ value \\
\hline \multicolumn{5}{|l|}{ Gender } \\
\hline Men & $34(10.1)$ & & & \\
\hline Women & $32(14.0)$ & 1.4 & $0.8-2.4$ & 0.159 \\
\hline \multicolumn{5}{|l|}{ Age groups (yr) } \\
\hline$\leq 29$ & $27(15.0)$ & 4.2 & $1.2-14.4$ & $0.021 * *$ \\
\hline $30-39$ & $36(11.7)$ & 3.2 & $0.9-10.6$ & $0.060 * *$ \\
\hline$\geq 40$ & $3(4.0)$ & 1 & & \\
\hline \multicolumn{5}{|l|}{ Qualification } \\
\hline Specialist & $20(11.8)$ & 1.1 & $0.6-1.8$ & 0.957 \\
\hline Non-specialist & $46(11.7)$ & & & \\
\hline \multicolumn{5}{|l|}{ Marital status } \\
\hline Single & $28(14.4)$ & 1.2 & $0.3-5.5$ & $0.838^{\dagger}$ \\
\hline Married & $36(10.2)$ & 0.8 & $0.2-3.7$ & $0.771^{\dagger}$ \\
\hline Divorce or widowed & $2(12.5)$ & 1 & & \\
\hline \multicolumn{5}{|l|}{ Chewing khat } \\
\hline Yes & $13(5.2)$ & & & \\
\hline No & $53(16.8)$ & 3.7 & $1.9-6.9$ & $<0.001$ \\
\hline \multicolumn{5}{|l|}{ Residence } \\
\hline House owner & $3(4.5)$ & & & \\
\hline Not a house owner & $63(12.7)$ & 3.1 & $0.9-10.2$ & 0.050 \\
\hline \multicolumn{5}{|l|}{ Duration of work in years } \\
\hline$\leq 10$ & $60(13.4)$ & 2.8 & $1.2-6.8$ & 0.015 \\
\hline$>10$ & $6(5.2)$ & & & \\
\hline \multicolumn{5}{|l|}{ Type of employment } \\
\hline Government only & $48(16.3)$ & 2.7 & $1.5-4.8$ & $<0.001$ \\
\hline Government and private sector & $18(6.7)$ & & & \\
\hline \multicolumn{5}{|c|}{ Hours of work with the government/wk ${ }^{\dagger}$} \\
\hline$\leq 40$ & $25(8.2)$ & & & \\
\hline$>40$ & $40(15.9)$ & 2.1 & $1.3-3.6$ & 0.005 \\
\hline \multicolumn{5}{|l|}{ Income from the government (YR)/mo ${ }^{\dagger}$} \\
\hline$\leq 40,000$ & $59(13.6)$ & 2.7 & $1.2-6.0$ & 0.013 \\
\hline$>40,000$ & $7(5.6)$ & & & \\
\hline
\end{tabular}

$\mathrm{OR}=$ odds ratio; $95 \% \mathrm{CI}=95 \%$ confidence interval. *: High burnout was defined as having high scores of emotional exhaustion ( $\geq 27)$, depersonalization $(\geq 13)$, and low score of personal accomplishment $(\leq 31)$. Analysis was performed using Chi-square test or simple logistic regression (**). $†$ The total number does not add up to 563 , because of missing response.

disturbance of home/family life by work ( $p=0.005)$, feeling of isolation $(p=0.027)$, dealing with patient's psychosocial problems $(p=0.017)$, not chewing khat $(p=0.005)$, long working hours $(p=0.017)$ and psychological morbidity $(p=0.016)$. The total model was significant $(p<0.005)$ and accounted for $25 \%$ of the variance (Table 6).

\section{Discussion}

High burnout was defined in this study as high scores in emotional exhaustion $(\geq 27)$, high scores in depersonalization $(\geq 13)$ and low scores in personal accomplishment $(\leq 31)$, and we combined the three subscales of burnout into one variable (high degree of burnout or burnout syndrome). This combination was done in two previous studies ${ }^{2,14}$. In this study, $11.7 \%$ of doctors met the criteria of burnout syndrome. This indicated that these doctors were experiencing depletion of emotional resources, cynicism and indifference about their patients and feelings of reduced competence and 
Table 5. Association between high level of burnout and sources of job stress in the workplace among doctors in Yemen $(\mathrm{N}=563)$

\begin{tabular}{rlccc}
\hline & Sources of job stress & OR & $95 \%$ CI & $p$ value \\
\hline 1 & Dealing with problem patients & 2.5 & $1.1-5.6$ & 0.040 \\
2 & Uncertainty and insecurity & 2.0 & $1.2-3.5$ & 0.011 \\
3 & Lack of comfortable rooms for doctors on call & 4.6 & $1.4-14.9$ & 0.006 \\
4 & Poor status in the eyes of your seniors & 2.3 & $1.2-4.2$ & 0.006 \\
5 & Dealing with patient's psychosocial problems & 2.3 & $1.4-3.9$ & 0.002 \\
6 & Feeling of isolation & 2.8 & $1.6-4.8$ & $<0.001$ \\
7 & Managing the practice & 2.0 & $1.2-3.4$ & 0.009 \\
8 & Working environment & 2.5 & $1.2-5.1$ & 0.014 \\
9 & Difficulty in finding a locum & 2.5 & $1.1-5.6$ & 0.026 \\
10 & Lack of appreciation from patients & 2.0 & $1.1-3.4$ & 0.015 \\
11 & Increased work loads & 9.2 & $2.8-29.7$ & $<0.001$ \\
12 & Disturbance of home/family life by work & 2.8 & $1.5-5.1$ & $<0.001$ \\
13 & Long working hours & 3.6 & $1.7-7.5$ & $<0.001$ \\
\hline
\end{tabular}

$\mathrm{OR}=$ odds ratio; $95 \% \mathrm{CI}=95 \%$ confidence interval. Analysis was performed using simple logistic regression. Reference category was "Not Agree".

Table 6. Significant predictors of high levels of burnout among doctors in Yemen (N=557): Multiple logistic regression

\begin{tabular}{|c|c|c|c|c|c|}
\hline Variables & & B & $\operatorname{Exp}(\mathrm{B})$ & 95\% CI for EXP (B) & $p$ value \\
\hline $\begin{array}{l}\text { Dealing with patient's } \\
\text { psychosocial problems }\end{array}$ & $\begin{array}{l}\text { Agree } \\
\text { Disagree }\end{array}$ & $\begin{array}{l}0.960 \\
\text { reference }\end{array}$ & $\begin{array}{c}2.6 \\
\text { reference }\end{array}$ & $\begin{array}{l}1.19-5.76 \\
\text { reference }\end{array}$ & $\begin{array}{l}0.017 \\
\text { reference }\end{array}$ \\
\hline Feeling of isolation & $\begin{array}{l}\text { Agree } \\
\text { Disagree }\end{array}$ & $\begin{array}{l}0.807 \\
\text { reference }\end{array}$ & $\begin{array}{l}2.2 \\
\text { reference }\end{array}$ & $\begin{array}{l}1.09-4.58 \\
\text { reference }\end{array}$ & $\begin{array}{l}0.027 \\
\text { reference }\end{array}$ \\
\hline $\begin{array}{l}\text { Disturbance of home/ } \\
\text { family life by work }\end{array}$ & $\begin{array}{l}\text { Agree } \\
\text { Disagree }\end{array}$ & $\begin{array}{l}1.570 \\
\text { reference }\end{array}$ & $\begin{array}{l}4.8 \\
\text { reference }\end{array}$ & $\begin{array}{l}1.62-14.28 \\
\text { reference }\end{array}$ & $\begin{array}{l}0.005 \\
\text { reference }\end{array}$ \\
\hline Chewing khat & $\begin{array}{l}\text { No } \\
\text { Yes }\end{array}$ & $\begin{array}{l}0.979 \\
\text { reference }\end{array}$ & $\begin{array}{c}2.7 \\
\text { reference }\end{array}$ & $\begin{array}{l}1.33-5.31 \\
\text { reference }\end{array}$ & $\begin{array}{l}0.005 \\
\text { reference }\end{array}$ \\
\hline Hours of work & $\begin{array}{l}>40 \mathrm{~h} \\
\leq 40 \mathrm{~h}\end{array}$ & $\begin{array}{l}0.702 \\
\text { reference }\end{array}$ & $\begin{array}{l}2.0 \\
\text { reference }\end{array}$ & $\begin{array}{l}1.13-3.60 \\
\text { reference }\end{array}$ & $\begin{array}{l}0.017 \\
\text { reference }\end{array}$ \\
\hline Psychological morbidity & $\begin{array}{l}\text { Yes } \\
\text { No }\end{array}$ & $\begin{array}{l}1.110 \\
\text { reference }\end{array}$ & $\begin{array}{c}3.0 \\
\text { reference }\end{array}$ & $\begin{array}{l}1.23-7.52 \\
\text { reference }\end{array}$ & $\begin{array}{l}0.016 \\
\text { reference }\end{array}$ \\
\hline
\end{tabular}

$\mathrm{B}=$ Regression estimates; $\operatorname{Exp}(\mathrm{B})$ gives the odds ratio; $95 \% \mathrm{CI}=95 \%$ confidence interval.

success with their patients. The prevalence of high burnout in this study was higher than that found by Woods $^{14)}$ where the prevalence was $2.5 \%$ (two respondents) among 81 rural community mental health counsellors at a rural mental health centre. In another study, only five $(4.2 \%)$ of 119 respondents satisfied all the 3 subscale scores for burnout syndrome, demonstrating high emotional exhaustion, high depersonalization, and low personal accomplishment ${ }^{2)}$.

In this study, doctors in the age group $\leq 29 \mathrm{yr}$ had significantly a higher prevalence of burnout syndrome than those in the age group $\geq 40$. This result was similar to those of previous studies that found a significant inverse correlation between emotional exhaustion and age $\mathrm{e}^{2,15,16)}$. Work characteristics are important factors in developing burnout as this study found a significant association between burnout and duration of work, hours of work, and income. In addition, thirteen out of 37 sources of stress in this study were associated significantly with burnout. Three of these sources of stress (disturbance of home/family life by work, feeling of isolation and dealing with patient's psychosocial problems) were significant 
predictors of burnout in multivariate analysis. These findings are consistent with previous studies that found that burnout was determined by working environment more than by personal factors and these previous studies also suggested that burnout was more of a social phenomenon rather than an individual one ${ }^{1,10)}$.

In this study, psychological morbidity was one of the significant predictors of high degree of burnout and this was consistent with a previous longitudinal study that found a reciprocal association between emotional exhaustion and stress (measured by GHQ12) ${ }^{7}$. Despite all the negative aspects of chewing $k h a t^{17)}$, unexpectedly, this study found that "not chewing khat" was a significant predictor of high degree of burnout. This finding invites further research to explore the relation between khat and burnout. Long working hours (>40 h/wk) was a significant predictor of high degree of burnout and this finding was similar to those reported in previous studies that found a significant association between burnout and hours worked per week ${ }^{2,18)}$.

Emotional exhaustion is the most important and the strongest component of burnout reflecting an excessive workload and loss of autonomy and control of the work environment ${ }^{1)}$. Its prevalence among Yemeni doctors (63.2\%) can be considered the highest among those reported in the literature which was ranges from $27 \%$ in Italy ${ }^{17)}$ to $54 \%$ in the United States ${ }^{2)}$. This can be explained by the fact that Yemen is a developing country with low financial and economical levels, poor workplace environment and scarce resources compared to developed countries. In addition, there is an absence of national organizations like those present in the developed countries to help doctors with stress ${ }^{19)}$. Yemeni doctors work in poor conditions and under-resourced hospitals; they also suffer from poor management, a lack of comfortable rooms for doctors on call (shared and semi-equipped room), low salaries (200 USD average monthly salary), difficulties in finding a locum and the arbitrary entrance of relatives to the departments during working hours that causes interruption and disturbance to doctors. Some of the main hospitals do not provide ultrasound or other radiological diagnostic equipment (except X-ray) in the emergency departments which may lead to fatal medical errors. The shortage of necessary diagnostic and treatment equipment in hospitals renders doctors unable to do their jobs properly and exposes them to blame from patients and their relatives or even violence. In addition, poor health indicators in the country ${ }^{9)}$ cause an extra ordinary burden on health care givers, particularly doctors. The Ministry of Health in Yemen acknowledged that the health system in Yemen is in a state of prolonged crisis and is one of the least favorable in the world. It has suffered from numerous structural and service delivery problems including poor quality of services, low staff morale, low efficiency, underutilization, lack of rationalization of service usage, and lack of equity in the distribution of facilities and manpower ${ }^{20)}$. All these defects in the health care system may affect doctors' health and their wellbeing, as well as their performance as health care givers.

This study has some limitations. The most important one is the cross sectional nature of this study which does not allow us to observe a causal relationship between the variables.

In conclusion, the prevalence of high degree of burnout as well as emotional exhaustion in Yemeni doctors was higher than those reported internationally. Three hundred and fifty-six doctors $(63.2 \%)$ scored high on the emotional exhaustion scale, indicating that they "had nothing left to give". These high figures can be considered bad indicators of the deteriorating health care system in Yemen and they should give rise to great concern and urgent action to change the current situation. Dealing with patient's psychosocial problems, feeling of isolation, disturbance of home/family life by work, hours of work and psychological morbidity were significant predictors of high degree of burnout. Therefore, training doctors in coping strategies is necessary to help them to overcome these stressors in the workplace. Health reforms should include financial management systems and the elimination of sources of stress in the work place. Further research on burnout is desirable and should include doctors in the rural areas of Yemen.

Acknowledgments: We thank all the respondents in this study and all those who helped with data collection. Special thanks to Dr. Sanjay Rampal and Dr. Azmi Tamil who helped with data analysis. We would like to thank Universiti Kebangsaan Malaysia for funding this study.

\section{References}

1) Maslach C, Schaufeli WB, Leiter MP. Job burnout. Annu Rev Psychol 2001; 52: 397-422.

2) Gabbe SG, Melville J, Mandel L, Walker E. Burnout in chairs of obstetrics and gynecology. Am J Obstet Gynecol 2002; 186: 601-12.

3) Barnett RC, Brennan RT, Gareis KC. A closer look at the measurement of burnout. J Appl Biobehav Res 1999; 4: 65-78.

4) Wood BD, Killion JB. Burnout among healthcare professionals. Radiology Management 2007; 48: 305.

5) Chopra S, Sotile WM, Sotile MO. Physician burnout. JAMA 2004; 29: 633.

6) Umehara K, Ohya Y, Kawakami N, Tsutsumi A, Fujimura M. Association of work-related factors with psychosocial job stressors and psychosomatic symptoms among Japanese pediatricians. J Occup Health 2007; 49: 467-81.

7) McManus IC, Winder BC, Gordon D. The causal links between stress and burnout in a longitudinal study of UK doctors. Lancet 2002; 359: 2089-90. 
8) Visser MRM, Smets EMA, Oort FJ, de Haes CJ. Stress, satisfaction and burnout among Dutch medical specialists. Can Med Assoc J 2003; 168: 271-75.

9) Ministry of Public Health (MoPH), Republic of Yemen. Annual statistical health report. [Online]. 2007 [cited 2009 May 9]; available from: URL: http://www.mophpye.org/arabic/docs/Report\%202007.pdf

10) Maslach C, Jackson SE. Maslach Burnout InventoryHuman Services Survey (MBI-HSS). In: Maslach C, Jackson SE, Leiter MP, editors. MBI Manual, 3rd ed. Palo Alto (CA): Consulting Psychologists Press; 1996. p. 192-8.

11) Schaufeli WB, Greenglass ER. Introduction to special issue on burnout and health. Psychol Health 2001; 16: 501-10.

12) Caplan RP. Stress, anxiety and depression in hospital consultants, general practitioners and senior health service managers. BMJ 1994; 309: 1261-63.

13) Ramirez A, Graham J, Richards MG, Cull A. Mental health of hospital consultants: The effects of stress and satisfaction at work. Lancet 1996; 347: 724-28.

14) Woods AP. The relationship of burnout to contextual work factors for a rural community mental health counsellors. PhD thesis, Duquesne University; 2005.
15) Campbell DA, Sonnad SS, Eckhauser FE, Campbell KK, Greenfield LJ. Burnout among American surgeons. Surgery 2001; 130: 696-705.

16) Ozyurt A, Hayran O, Sur H. Predictors of burnout and job satisfaction among Turkish physicians. Q J Med 2006; 99: 161-69.

17) Cox G, Rampes H. Adverse effects of khat: A review. Advances in Psychiatric Treatment 2003; 9: 456-63.

18) Klersy C, Aliria C, Martinelli V, et al. Burnout in health care providers of dialysis service in Northern Italy-A multicentre study. Nephrology Dialysis Transplantation 2007; 22: 2283-90.

19) Royal College of General Practitioner (RCGP). RCGP information sheets no 22. Stress and general practice. [Online]. 2005 [cited 2008 April 12]; available from: URL: http://www.rcgp.org.uk/information/ publications/information/PDFInfo/22\%20\%20FEB05.pdf

20) Ministry of Public Health (MoPH), Republic of Yemen. Health sector reform in the Republic of Yemen. Strategy for reform. [Online]. 2000 [cited 2008 April 13]; available from: URL: http://www.mophp-ye.org/docs/ HSR_Strategy.pdf 